OPEN ACCESS

Edited by:

László Virág,

University of Szeged, Hungary

Reviewed by:

Lasse Skibsbye,

Lundbeck, Denmark

Ursula Ravens,

Dresden University of Technology,

Germany

*Correspondence:

Sami Noujaim

snoujaim@usf.edu

tThese authors have contributed equally to this work

Specialty section:

This article was submitted to Cardiovascular and Smooth Muscle Pharmacology, a section of the journal

Frontiers in Pharmacology

Received: 13 August 2019

Accepted: 31 October 2019

Published: 27 November 2019

Citation:

Tobón C, Palacio LC, Chidipi B, Slough DP, Tran T, Tran N, Reiser M,

Lin Y-S, Herweg B, Sayad D,

Saiz $J$ and Noujaim $S$ (2019) The

Antimalarial Chloroquine Reduces the Burden of Persistent Atrial Fibrillation.

Front. Pharmacol. 10:1392.

doi: 10.3389/fphar.2019.01392

\section{The Antimalarial Chloroquine Reduces the Burden of Persistent Atrial Fibrillation}

\author{
Catalina Tobón ${ }^{1 \dagger}$, Laura C. Palacio ${ }^{1 \dagger}$, Bojjibabu Chidipi2t, Diana P. Slough ${ }^{3 \dagger}$, Thanh Tran ${ }^{4}$, \\ Nhi Tran ${ }^{4}$, Michelle Reiser ${ }^{2}$, Yu-Shan Lin ${ }^{3}$, Bengt Herweg ${ }^{4}$, Dany Sayad ${ }^{4}$, Javier Saiz ${ }^{5}$ \\ and Sami Noujaim ${ }^{2 *}$ \\ ${ }^{1}$ MATBIOM, Universidad de Medellin, Medellin, Colombia, ${ }^{2}$ Molecular Pharmacology and Physiology Department, University \\ of South Florida Morsani College of Medicine, Tampa, FL, United States, ${ }^{3}$ Department of Chemistry, Tufts University, \\ Medford, MA, United States, ${ }^{4}$ Cardiology Department, University of South Florida Morsani College of Medicine, Tampa, FL, \\ United States, ${ }^{5} \mathrm{Ci}^{2} \mathrm{~B}$, Universitat Politècnica de València, Valencia, Spain
}

In clinical practice, reducing the burden of persistent atrial fibrillation by pharmacological means is challenging. We explored if blocking the background and the acetylcholineactivated inward rectifier potassium currents $\left(I_{K 1}\right.$ and $\left.I_{K A C h}\right)$ could be antiarrhythmic in persistent atrial fibrillation. We thus tested the hypothesis that blocking $I_{\mathrm{K} 1}$ and $I_{\mathrm{KACh}}$ with chloroquine decreases the burden of persistent atrial fibrillation. We used patch clamp to determine the $\mathrm{IC}_{50}$ of $\mathrm{I}_{\mathrm{K} 1}$ and $\mathrm{I}_{\mathrm{KACh}}$ block by chloroquine and molecular modeling to simulate the interaction between chloroquine and Kir2.1 and Kir3.1, the molecular correlates of $I_{\mathrm{K} 1}$ and $I_{\text {KACh }}$. We then tested, as a proof of concept, if oral chloroquine administration to a patient with persistent atrial fibrillation can decrease the arrhythmia burden. We also simulated the effects of chloroquine in a 3D model of human atria with persistent atrial fibrillation. In patch clamp the $\mathrm{IC}_{50}$ of $\mathrm{I}_{\mathrm{K} 1}$ block by chloroquine was similar to that of $\mathrm{I}_{\mathrm{KACh}}$. A 14-day regimen of oral chloroquine significantly decreased the burden of persistent atrial fibrillation in a patient. Mathematical simulations of persistent atrial fibrillation in a 3D model of human atria suggested that chloroquine prolonged the action potential duration, leading to failure of reentrant excitation, and the subsequent termination of the arrhythmia. The combined block of $I_{K 1}$ and $I_{K A C h}$ can be a targeted therapeutic strategy for persistent atrial fibrillation.

Keywords: chloroquine, persistent atrial fibrillation, potassium inward rectifiers, $I_{K A C h}, I_{K 1}$

\section{INTRODUCTION}

Atrial fibrillation (AF) is the most common heart rhythm abnormality and its incidence and prevalence are increasingly alarming. In addition to increasing mortality, AF is a known risk factor for stroke (Wolf et al., 1991), dementia (Liao et al., 2015; Singh-Manoux et al., 2017), and cardiac contractile dysfunction (Schotten et al., 2002). Pharmacological rhythm control therapy for AF remains attractive, however, when AF becomes persistent, pharmacotherapy is frequently ineffective (Zimetbaum, 2012).

Chloroquine, an antimalarial 4-aminoquinoline, has been suggested to have antiarrhythmic properties through unknown mechanisms (Burrell and Martinez, 1958; Harris et al., 1988), and was shown to have a safe cardiac electrophysiological profile (Wozniacka et al., 2006; Teixeira et al., 
2014). Our previous work suggested that chloroquine terminates different forms of AF in animal models, in part, due to its ability to block potassium inward rectifiers (Noujaim et al., 2010; Filgueiras-Rama et al., 2012; Takemoto et al., 2018).

In persistent $\mathrm{AF}$, the acetylcholine-activated inward rectifier potassium current $\mathrm{I}_{\mathrm{KACh}}$ (molecular correlates are Kir3.1 and Kir3.4) was shown to be constitutively active and the inward rectifier potassium current $\mathrm{I}_{\mathrm{K} 1}$ (molecular correlates Kir2.1 and Kir2.3) has been shown to be upregulated (Voigt et al., 2010; Dobrev and Nattel, 2011). The constitutively active $\mathrm{I}_{\text {KACh }}$ could be considered as a background inward rectifier, which along with the increased $\mathrm{I}_{\mathrm{K} 1}$ may contribute to the shortening of the action potential duration and to create a substrate for the formation of stable, high frequency electrical rotors that maintain fibrillation (Atienza and Jalife, 2007; Noujaim et al., 2007). Consequently, blocking inward rectifiers could potentially be antiarrhythmic in the setting of persistent AF.

Recently, we used structural biology approaches to map the binding pocket of chloroquine in the intracellular domain of Kir3.1 (Takemoto et al., 2018). Chloroquine blocked $\mathrm{I}_{\mathrm{KACh}}$ by binding at a specific site in the Kir3.1 intracellular ion permeation pathway (Takemoto et al., 2018). Previous work by us and others showed that chloroquine also blocks $\mathrm{I}_{\mathrm{k} 1}$ (Rodriguez-Menchaca et al., 2008; Noujaim et al., 2010). In this study, we tested in a patient with persistent $\mathrm{AF}$ whether chloroquine can reduce the arrhythmia burden, and we further explored the antiarrhythmic effects of chloroquine in a 3D model of the human atria with persistent AF.

\section{METHODS}

\section{Patch Clamp}

Experiments were performed as described earlier (Noujaim et al., 2011; Takemoto et al., 2018). HEK293 cells stably co-transfected with Kir3.1 and Kir3.4 were generously provided by the Bayliss Laboratory (University of Virginia), and HEK293 cells stably transfected with Kir2.1 were generously provided by the Jalife Laboratory (University of Michigan). Currents were recorded using EPC 800 amplifier (HEKA Elektronik, Lambrecht/Pfalz), A/D converter (Digidata 1550B plus Hum Silencer, Molecular Devices, San Jose, CA), and the pClamp 10.6 PC software (Molecular Devices). Analysis was performed with Clampfit 10.6 (pClamp, Molecular Devices) and OriginPro software packages (version 2018, Microcal). The patch pipettes had a resistance of 2.5-3M $\Omega$. After $\mathrm{G} \Omega$ seal formation, whole cell recordings were performed at room temperature (around $24^{\circ} \mathrm{C}$ ). For $\mathrm{I}_{\mathrm{KACh}}$, the bath solution contained (in $\mathrm{mM}$ ) $90 \mathrm{NaCl}, 50 \mathrm{KCl}, 1 \mathrm{CaCl}_{2}, 2$ $\mathrm{MgCl}_{2}, 10 \mathrm{HEPES}, 10$ glucose, and the $\mathrm{pH}$ adjusted to 7.4. The pipette internal solution contained (in $\mathrm{mM}$ ) $100 \mathrm{~K}$-aspartate, 10 $\mathrm{NaCl}, 40 \mathrm{KCl}, 5 \mathrm{Mg}$-ATP, 2 EGTA, 0.1 GTP-Tris, and 10 HEPES at $\mathrm{pH}$ 7.2. For $\mathrm{I}_{\mathrm{K} 1}$, the bath solution contained (in $\mathrm{mM}$ ) 148 $\mathrm{NaCl}, 0.4 \mathrm{NaH}_{2} \mathrm{PO}_{4}, 1 \mathrm{MgCl}_{2}, 5.4 \mathrm{KCl}, 1.8 \mathrm{CaCl}_{2}, 5.5$ glucose, 15 HEPES, pH 7.4, and the pipette internal solution contained (in $\mathrm{mM}), 150 \mathrm{KCl}, 1 \mathrm{MgCl}_{2}$, 5 EGTA, 5 HEPES, 5 phosphocreatine, $4.4 \mathrm{~K}_{2} \mathrm{ATP}$, and $\mathrm{pH}$ 7.2. $\mathrm{I}_{\mathrm{KACh}}$ and $\mathrm{I}_{\mathrm{K} 1}$ were measured as the $1 \mathrm{mM}$ $\mathrm{BaCl}_{2}$ sensitive current. Concentration-response curves and $\mathrm{IC}_{50}$ for currents inhibition at $-140 \mathrm{mV}$ were determined with Prism 7 software using the standard variable slope equation $Y=1 /(1+$ $10^{(\log I C 50-X) * \text { Slope })}$.

\section{Molecular Docking of Chloroquine Into Kir2.1 and Kir3.1}

As we previously described, the intracellular domain of tetrameric Kir2.1 (PDB: 1U4F) (Pegan et al., 2005) and Kir3.1 (PDB: 1U4E) (Pegan et al., 2005) were used for the docking simulations. The SMILES string for chloroquine was obtained from Drugbank (Wishart et al., 2008) (Accession Number: DB00608). The Kir2.1 and Kir3.1 proteins, and chloroquine were prepared using the Protein Preparation Wizard and LigPrep in Schrodinger's Maestro (Sastry et al., 2013), respectively. The protonation state of the drug was generated at a target pH of 7.0 in Epik (Shelley et al., 2007; Greenwood et al., 2010). The ligand was energy minimized with the OPLS_2005 force field (Shivakumar et al., 2010). A set of grids was created to map the proteins topologies before docking. The grids were generated using $60 \times 60 \times 60$ points in the $x, y$, and $z$ directions and centered around the aqueous channel with a spacing of 0.375 A. Docking was performed with the Lamarckian genetic algorithm, with the population size set to 150 , the number of generations set to 27,000 and the number of energy evaluations set to 2,500,000. Using Autodock 4.2 (Morris et al., 2009), one thousand runs were performed. The lowest energy poses from molecular docking were analyzed. Hydrogen bond analysis was performed using Visual Molecular Dynamics (Humphrey et al., 1996).

\section{Estimation of Blocking Ability of Chloroquine}

A voxel grid was generated using the atomic coordinates of the lowest energy pose from molecular docking of the tetrameric Kir2.1 or Kir3.1 bound to chloroquine. In this grid, each voxel was a cube of $0.2 \times 0.2 \times 0.2 \AA$. The van der Waals radius of each atom (Iijima et al., 1987) was used to fill the corresponding number of cubes. The use of the discrete grid allowed for a probe to search the space in the aqueous ion-permeation pathway. The probes were Voxel-approximated spheres with radii ranging from $1.4 \AA$ (the ionic radius of a bare $\mathrm{K}^{+}$ion) to $3.9 \AA$ in $0.1 \AA$ increments. Three ångströms is the radius of a solvated $\mathrm{K}^{+}$ion up to its first hydration shell (Mahler and Persson, 2012). Originating from the extracellular opening of the channel, the probes were pushed longitudinally through the channel towards the intracellular side. If, at any point in the pathway, the probe was unable to proceed further, the probe's lateral position was adjusted in order to search all possible paths through the channel. The channel was considered blocked at a given probe radius if the probe was unable to find a path to move past chloroquine.

\section{Human Study}

A 67 year old female with history of tobacco use, persistent AF (AF sustained for more than seven days, and less than a year), and no other significant past medical history including no known coronary artery disease, was enrolled in this study. Institutional Review Board approval was obtained at the University of South Florida, Tampa, USA, and the study conformed to the 
principles outlined in the Declaration of Helsinki. Prior workup revealed normal blood pressure. Her laboratory values showed normal kidney and liver function tests. Echocardiography was unremarkable for structural heart disease, with an ejection fraction $>50 \%$. The patient has been on Apixaban and Metoprolol, and continued to be on these medications during the study. The patient gave informed consent, was equipped with a Cardionet monitor, and received the chloroquine regimen for amebiasis treatment, consisting of $600 \mathrm{mg}$ chloroquine base once daily for 2 days, followed by $300 \mathrm{mg}$ daily for 12 days. She was continuously monitored for the duration of chloroquine treatment. A previous Holter monitor recording (ZIO XT Patch) for 12 days obtained two months prior, was reviewed and showed that the patient had been continuously in AF, with a burden of $100 \%$. Additionally, 12 lead ECG was recorded 3 days before and on the day of chloroquine regimen initiation, confirming that the patient was in $\mathrm{AF}$ in both instances.

\section{Mathematical Simulations of Persistent Atrial Fibrillation in a 3D Model of Human Atria}

The Courtemanche-Ramirez-Nattel membrane formalism (Courtemanche et al., 1998) was implemented to simulate the human atrial cell action potential. Cholinergic activity, a factor that promotes AF, was included in the model by implementing the following $I_{\text {KACh }}$ equation developed by Kneller (Kneller et al., 2002):

$$
I_{K A C h}=\left(\frac{10}{1+9.13652 / A C h^{0.477811}}\right)\left(0.0517+\frac{0.4516}{1+e^{V_{m}+59.53} / 17.18}\right)\left(V-E_{K}\right)
$$

where $V_{m}$ is the membrane potential, $A C h$ is the acetylcholine concentration and $E_{K}$ is the potassium equilibrium potential.

Based on experimental data (Workman et al., 2001; Van Wagoner, 2003), the cell model was modified in order to reproduce electrophysiological conditions of persistent AF: the maximum conductance of $\mathrm{I}_{\mathrm{K} 1}$ was increased by $100 \%$, the maximum conductance of transient potassium current $\left(\mathrm{I}_{\mathrm{to}}\right)$ and delayed rectifier potassium current $\left(\mathrm{I}_{\mathrm{Kur}}\right)$ were decreased by $50 \%$, and the maximum conductance of L-type calcium current $\left(\mathrm{I}_{\mathrm{CaL}}\right)$ was decreased by $70 \%$ and for the constitutively active $\mathrm{I}_{\mathrm{KACh}}, 5$ $\mathrm{nM}$ of acetylcholine was simulated.

A realistic three-dimensional (3D) model of human atria including the main anatomical structures: left and right atria, twenty pectinate muscles, fossa ovalis, Bachmann's bundle, crista terminalis, left and right appendages, pulmonary veins, caval veins, atrioventricular rings and coronary sinus, was previously developed (Tobon et al., 2013). The model also includes three different pathways for the inter-atrial conduction, specific fiber orientations in 42 different atrial regions, heterogeneous tissue conductivity, anisotropy ratios and heterogeneous cellular properties. The wall of the atrial model is a monolayer surface, except the Bachmann's bundle and the pectinate muscles, which are solid structures. The model is composed of 52,906 hexahedral elements with a spatial resolution ranging from 300 to $700 \mu \mathrm{m}$.

The mathematical atrial cell model coupled with the $3 \mathrm{D}$ model was used to simulate a persistent AF episode. AF was generated with an S1-S2 stimulation protocol. S1 consisted of a train of ten stimuli with a basic cycle length of 1,000 ms, applied to the sinus node area, simulating sinus rhythm. After the last S1 stimulus, 6 ectopic S2 beats at $130 \mathrm{~ms}$ cycle length were delivered to the right superior pulmonary vein. Action potential propagation in the tissue was modeled using the monodomain reaction-diffusion equation:

$$
\frac{1}{S_{v}} \nabla \cdot\left(D \nabla V_{m}\right)=C_{m} \frac{\partial V_{m}}{\partial t}+I_{i o n}-I_{s t i m}
$$

where, $S_{v}$ corresponds to the surface-to-volume ratio (range from 0.0086 to 0.02$), D$ is the conductivity tensor, $C_{m}$ is the membrane capacitance $(100 \mathrm{pF}), I_{\text {ion }}$ is the total ionic current that crosses the cell membrane and $I_{\text {stim }}$ is the stimulus current $(28 \mathrm{pA} / \mathrm{pF})$. Equations were numerically solved using EMOS software (Heidenreich et al., 2010), which is a parallel code that implements the finite element method and operator splitting for solving the monodomain model. The time step was fixed to $0.001 \mathrm{~ms}$. Simulation of $2 \mathrm{~s}$ of atrial activity required $32 \mathrm{~h}$ on a computing node with 12 dual core AMD Opteron Processors 2,218 clocked at 2.6 GHz.

Pseudo-unipolar atrial electrograms (EGMs) in the 3D model at $0.2 \mathrm{~mm}$ from the surface were simulated. The extracellular potential $\left(\Phi_{e}\right)$ in the endocardial atrial surface was computed using the large volume conductor approximation

$$
\phi_{e}(r)=-K \iiint \nabla^{\prime} V_{m}\left(r^{\prime}\right) \cdot \nabla^{\prime}\left[\frac{1}{r^{\prime}-r}\right] d v
$$

where $K(-0.0398)$ is a constant that includes the ratio of intracellular and extracellular conductivities, $\nabla^{\prime} V_{m}$ is the spatial gradient of transmembrane potential, $r$ is the distance from the source point $(x, y, z)$ to the measuring point $\left(x^{\prime}, y^{\prime}, z^{\prime}\right)$ and $d v$ is the differential volume. EGMs at different points were visually inspected in order to analyze their morphologies as single, double or fractionated potentials. Double potentials were defined as EGMs with two negative or positive deflections and fractionated electrograms were defined as those exhibiting multiple (more than two) deflections. EGMs were processed with a 40-250 $\mathrm{Hz}$ band-pass filter, rectified and low-pass filtered at $20 \mathrm{~Hz}$. Subsequently, spectral analysis of the signals was performed with a fast Fourier transform. The dominant frequency (DF) defined as the frequency corresponding to the highest peak of the power spectrum was calculated.

\section{Modeling the Effect of Chloroquine on Potassium Currents}

To develop a basic model of the effect of chloroquine on the major potassium currents that this drug has been shown to block $\left(\mathrm{I}_{\mathrm{KACh}}, \mathrm{I}_{\mathrm{K} 1}\right.$, and $\mathrm{I}_{\mathrm{Kr}}$ ) (Sanchez-Chapula et al., 2001), we used the steady state fraction of block $(f)$, as done previously (Duarte M et al., 2013):

$$
f=1 /\left(1+I C_{50} /[C]\right)
$$

where $C$ is the chloroquine concentration. The Hill equation was used to fit the Concentration-response relationships for 
chloroquine block. In this model, the channels kinetics were considered unchanged in the presence of the chloroquine. The $\mathrm{IC}_{50}$ for $\mathrm{I}_{\mathrm{KACh}}$ and $\mathrm{I}_{\mathrm{K} 1}$ block by chloroquine were used from Figures 1 and 2 and our earlier work (Noujaim et al., 2010) $(0.97 \mu \mathrm{M}$ for $\mathrm{I}_{\mathrm{K} 1}$ and $1.0 \mu \mathrm{M}$ for $\left.\mathrm{I}_{\mathrm{KACh}}\right)$. For $\mathrm{I}_{\mathrm{Kr}}$, we used an $\mathrm{IC}_{50}$ of $2.5 \mu \mathrm{M}$ as reported by Traebert et al in HEK293 cells (Traebert et al., 2004). The simulated fraction of block curve for $\mathrm{I}_{\mathrm{KACh}}$ current fit well the experimental data shown in Figures 1 and 2, where $(1-f)$. $100 \%$ is the remaining current. After $5 \mathrm{~s}$ of baseline AF simulation, chloroquine was applied at increasing concentrations, from $1.0 \mu \mathrm{M}$ to $8.7 \mu \mathrm{M}$, in order to simulate $\sim 50 \%$ to $\sim 90 \%$ block of $\mathrm{I}_{\mathrm{K} 1}$ and $\mathrm{I}_{\mathrm{KACh}}$, and from $1.0 \mu \mathrm{M}$ to $25 \mu \mathrm{M}$, in order to simulate $30 \%$ to $90 \%$ block of $\mathrm{I}_{\mathrm{Kr}}$. We investigated the effects of chloroquine on AF dynamics by blocking either $\mathrm{I}_{\mathrm{K} 1}, \mathrm{I}_{\mathrm{KACh}}$ or $\mathrm{I}_{\mathrm{Kr}}$ alone, or by blocking both $\mathrm{I}_{\mathrm{K} 1}$ and $\mathrm{I}_{\mathrm{KACh}}$, or by blocking the three currents. Action potential duration at $90 \%$ repolarization $\left(\mathrm{APD}_{90}\right)$ and the resting membrane potential (RMP) in a left atrial single cell were measured. All simulations were halted $2 \mathrm{~s}$ after chloroquine application.

\section{RESULTS}

\section{Chloroquine Block of $I_{K 1}$ and $I_{K A C h}$}

Our earlier study using modeling, and protein NMR, suggested that chloroquine binds the intracellular domain of Kir3.1, at the level of amino acids F255 and D260 (Takemoto et al., 2018). Here, we conducted similar molecular docking simulations in order to compare the binding of chloroquine to Kir2.1 and Kir3.1. For each complex, one thousand docking runs were performed. The lowest energy poses for ligand-protein interactions were further studied. Figures $\mathbf{1 A}$ and $\mathbf{2 A}$, left panels, are zoomed in views of the tetrameric Kir2.1 (Figure 1A) and Kir3.1 (Figure 2A) channels, represented by gray ribbons, with the docked chloroquine depicted in cyan. In Kir2.1 (Figure 1A), the tertiary amine of chloroquine hydrogen-bonded to residue E224 of subunit B (black circles), and the aminoquinoline ring formed a hydrogen bond with the carbonyl oxygen of the diametrically opposed E224 of subunit D. The binding energy of chloroquine to Kir2.1 was $-6.09 \mathrm{Kcal} /$ mol. In Kir3.1 (Figure 2A), the tertiary amine of chloroquine hydrogen-bonded to residue D260 of subunit B (black circles), and the aminoquinoline ring was in proximity to the F255 ring of the adjacent subunit $\mathrm{A}$. The binding energy of the ligand to the channel was $-6.37 \mathrm{Kcal} / \mathrm{mol}$. The Van der Waals representations of the Kir2.1 and Kir3.1 in complex with chloroquine are shown from the extracellular bird's eye views (Figures 1A and 2A, bottom panels). The ion permeation pathways are in the middle, and the white arrows point to chloroquine which is shown in cyan. We then used patch clamp to compare the $\mathrm{IC}_{50}$ for chloroquine block of $\mathrm{I}_{\mathrm{K} 1}$ (Figure 1B) and $\mathrm{I}_{\mathrm{KACh}}$ (Figure 2B). Top panels are representative

\section{A}
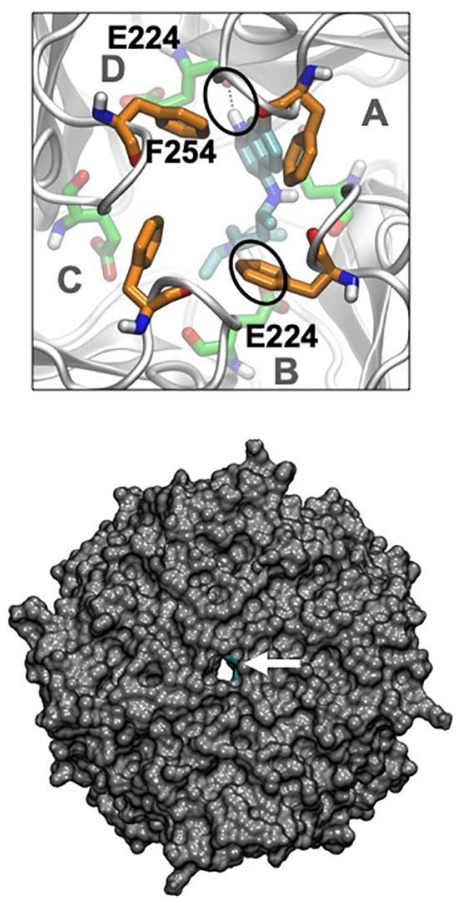

B
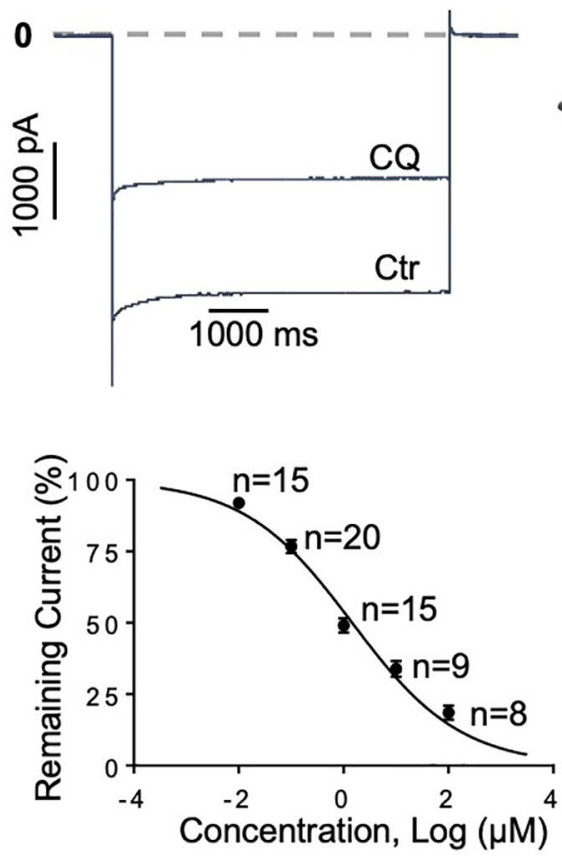
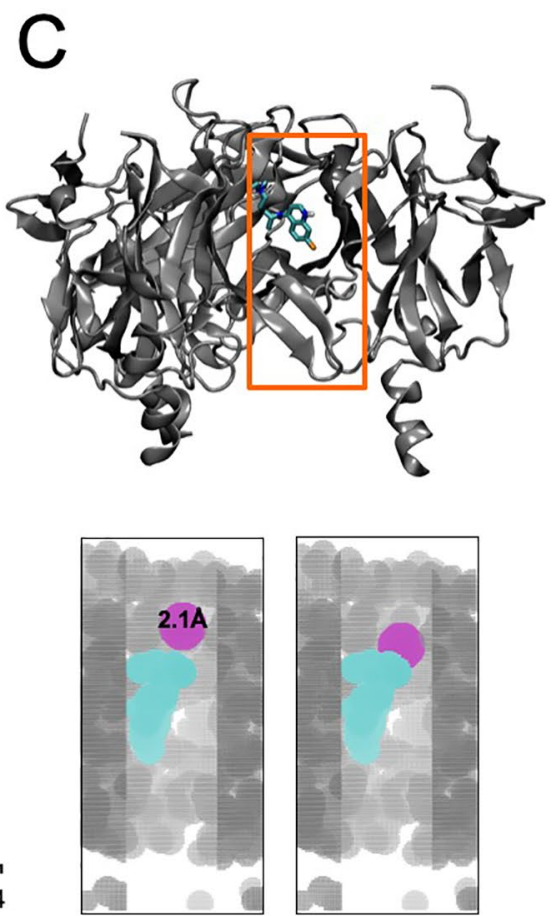

FIGURE 1 | $\left.\right|_{\mathrm{K} 1}$ block with chloroquine. (A) Docking of chloroquine in the intracellular domain of Kir2.1. The lowest energy pose is shown. Chloroquine makes hydrogen bonds with residue E224 from subunit B and with E224 from subunit D (black circles). Bottom panel: Extracellular bird's eye views of the van der Waals representation of the channel (gray) in complex with chloroquine (cyan). Chloroquine blocks the ion permeation pathway. (B) Barium sensitive $I_{K 1}$ traces in response to -140mV step pulses from a holding potential of $0 \mathrm{mV}$ in the presence of $1 \mu \mathrm{M}$ chloroquine $(\mathrm{CQ})$. Concentration-response curves. $\mathrm{IC}_{50}$ for chloroquine block of $\mathrm{I}_{\mathrm{K} 1}$ : $1.3 \mu \mathrm{M}$, Hill $\mathrm{Slope}=$ $-0.42, R^{2}=0.9$. (C) Top panel: Longitudinal view of chloroquine bound to Kir2.1. Orange box denotes the voxelated part of the channel shown below. Bottom panel: Voxelation of Kir2.1 ion permeation pathway (grey) in complex with chloroquine (cyan). A probe (magenta) of radius $2.1 \AA ̊$ or larger, is blocked by chloroquine. 


\section{A}
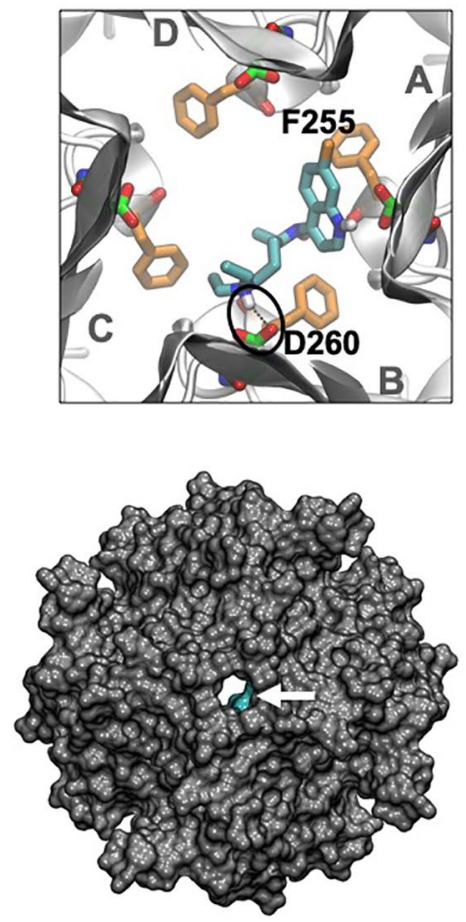

B
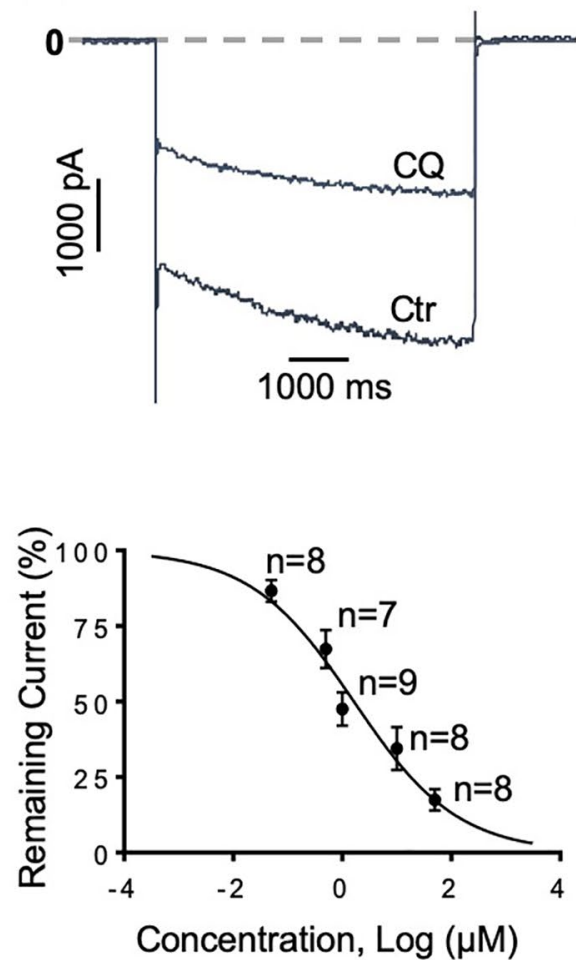

C
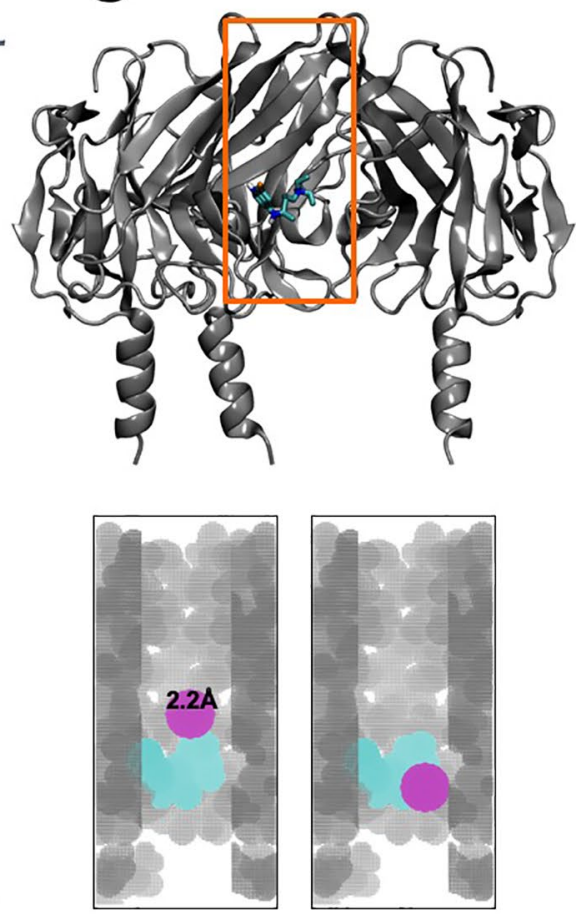

FIGURE 2 | $\left.\right|_{\text {KACh }}$ block with chloroquine. (A) Docking of chloroquine in the intracellular domain of Kir3.1. The lowest energy pose is shown. The D260 and F255 residues from each of the four Kir3.1 subunits are shown in green and orange sticks respectively. The tertiary amine nitrogen of chloroquine (cyan sticks) forms a hydrogen bond (black circle) with the side chain of D260 in the B subunit, while the aminoquinoline ring of chloroquine is in close proximity to the phenylalanine ring of F255 in the A subunit. Van der Waals representations of the channel bound to the drugs (cyan) viewed from the extracellular side is shown in the bottom panel. (B) Barium sensitive $\mathrm{I}_{\text {KACh }}$ traces in response to $-140 \mathrm{mV}$ step pulses from a holding potential of $-20 \mathrm{mV}$ in the presence of $1 \mu \mathrm{M}$ chloroquine (CQ). (B) Concentration-response curves. IC50 for chloroquine block of $\mathrm{I}_{\mathrm{KACh}}: 1.2 \mu \mathrm{M}$, Hill Slope $=-0.48, \mathrm{R}^{2}=0.74$. (C) Top panel: Longitudinal view of chloroquine bound to Kir3.1. Orange box denotes the voxelated part of the channel shown below. Bottom panel: Voxelation of Kir3.1 ion permeation pathway (grey) in complex with chloroquine (cyan). A probe (magenta) of radius $2.2 \AA$ or larger, is blocked by chloroquine.

current traces in response to voltage steps in the presence of $1 \mu \mathrm{M}$ chloroquine. In the concentration-response curves, the $\mathrm{IC}_{50} \mathrm{~s}$ of $\mathrm{I}_{\mathrm{K} 1}$ and $\mathrm{I}_{\mathrm{KACh}}$ block by chloroquine at $-140 \mathrm{mV}$ were $1.3 \mu \mathrm{M}$ and $1.2 \mu \mathrm{M}$ respectively. Subsequently, we voxelated the models for Kir2.1 and Kir3.1 in order to verify that in the docked structures, chloroquine is able to block the flow of potassium ions through the intracellular ion permeation pathway (Figures 1C and 2C). The intracellular domains of Kir2.1 and 3.1 are shown in the longitudinal view, with the front subunit removed, and bound chloroquine (cyan sticks) is exposed. In Kir2.1, chloroquine binds closer to the G loop area, while in Kir3.1, chloroquine binds towards the intracellular mouth of the permeation pathway. The orange box denotes the voxelated part of the channels presented in the bottom panels of Figures 1C and 2C. It was found that in Kir2.1, a probe (magenta sphere) of radius $\geq 2.1 \AA$ was blocked by the drug, while probes with radii $<2.1 \AA$ passed through. In Kir3.1, a probe of radius $\geq 2.2 \AA$ was blocked by the drug, while probes with radii $<2.2 \AA$ passed through. $3.0 \AA$ is the radius of a solvated $\mathrm{K}^{+}$ion up to its first hydration shell. These results are in agreement with the patch clamp experiments which showed similar $\mathrm{IC}_{50}$ for chloroquine block of Kir2.1 and Kir3.1.

\section{Chloroquine Treatment in a Patient With Persistent AF}

As proof of concept, we tested in a patient with persistent atrial fibrillation, whether chloroquine can modify the AF burden. This 67 year old female was non-diabetic, non-hypertensive, a previous smoker, with no known structural heart or coronary artery disease but with known persistent AF. Figure 3A shows the daily AF burden extracted from Holter monitoring. At baseline, the patient was in uninterrupted, persistent AF. Figure 3B is a 12 lead ECG taken on the day of study initiation in order to confirm the presence of AF. After initiation of chloroquine treatment, AF burden was significantly reduced, with extensive periods of normal sinus rhythm, and the first conversion to normal sinus rhythm happened on the third day of treatment. Figure $3 \mathrm{C}$ shows Holter traces at baseline (top), immediately before treatment initiation (middle), where the patient was in AF, and during sinus rhythm on the third day of the oral chloroquine regimen (bottom). The patient did not have premature ventricular contractions while on chloroquine. The QT and QTc intervals while in AF, at the beginning of the study, were $418 \mathrm{~ms}$ and $428 \mathrm{~ms}$ respectively, and at the end of study, the QT and QTc intervals while in sinus 


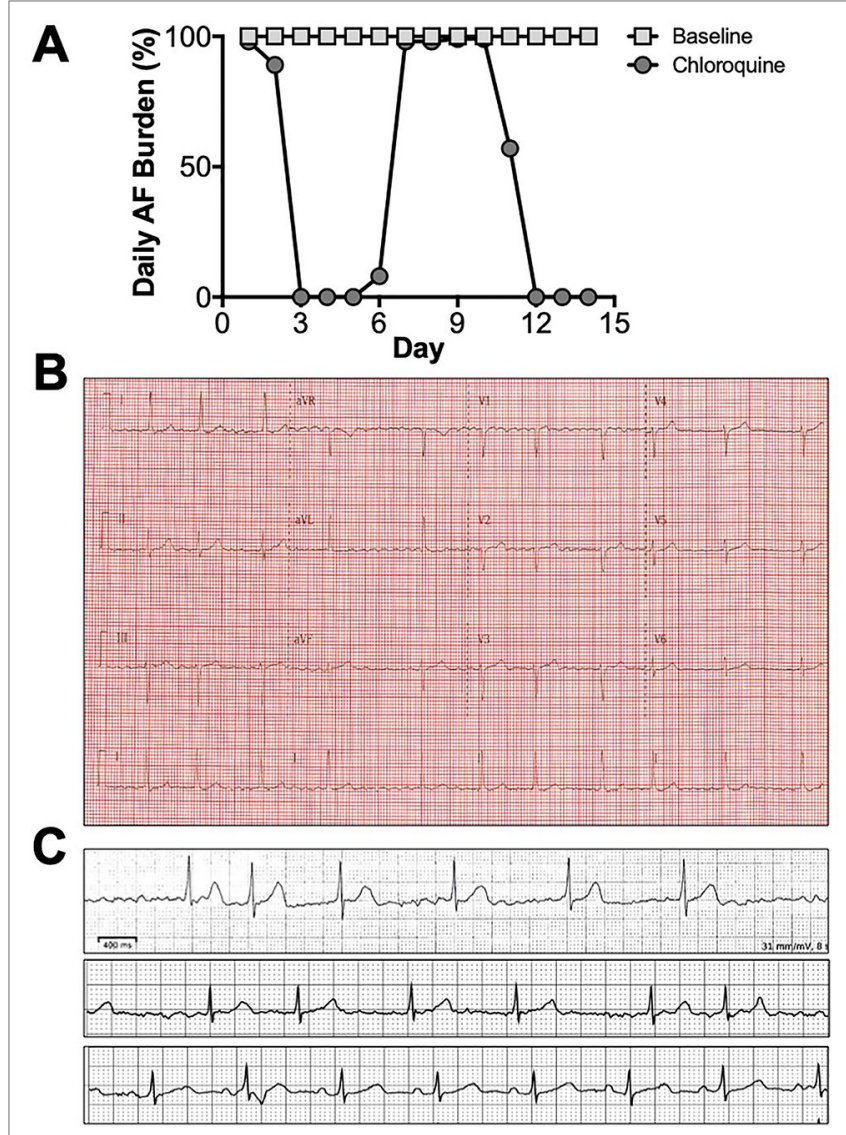

FIGURE 3 | Chloroquine effects on persistent AF. (A) Daily AF burden for 14 days in Holter monitoring at baseline, and for 14 days upon initiation of oral chloroquine (amebiasis treatment regimen). (B) 12 lead ECG on the day of chloroquine initiation, confirming the presence of AF. (C) Holter ECG strips from baseline (top), right before treatment initiation (middle), and on the $3^{\text {rd }}$ day of treatment when AF converted to sinus rhythm (bottom).

rhythm were $450 \mathrm{~ms}$ and $461 \mathrm{~ms}$. After the chloroquine regimen was completed, and upon follow up, the patient was back in atrial fibrillation as documented by a 12 lead ECG.

\section{Effects of Chloroquine on Persistent AF in a 3D Model of Human Atria}

A model of persistent AF was initiated by ectopic activity in the right superior pulmonary vein, and the arrhythmia was maintained by two stable rotors located in the posterior wall of the left atrium, near the left superior pulmonary vein and in the superior vena cava (Figure 4A). The calculated EGMs at sites 1 , and 3 , where the rotors were localized, showed double and fractionated potentials with low amplitude (Figure 4B). This occurred when the tip of the rotors pivoted at these locations, where the excitable but unexcited core resulted in multiple low amplitude deflections in the EGM. EGMs with single and double potentials were observed at sites 2 and 4 and were generated by wavefronts emanating from rotors and by wavebreaks at anatomical structures such as the crista terminalis and pectinate muscles. The DF was about $11 \mathrm{~Hz}$ (Figure 4B).

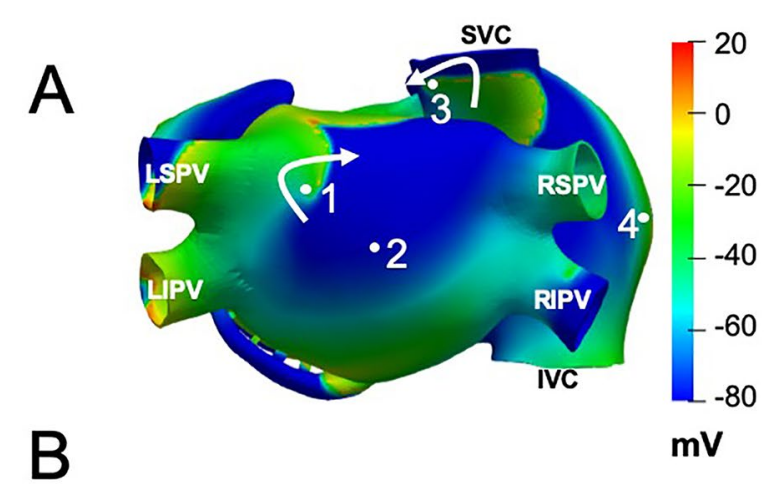

$\mathrm{DF}=11 \mathrm{~Hz}$

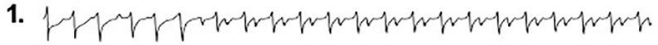

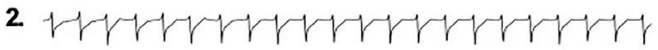

3.

4. мppppppppppppppppppppp

\section{$500 \mathrm{~ms}$}

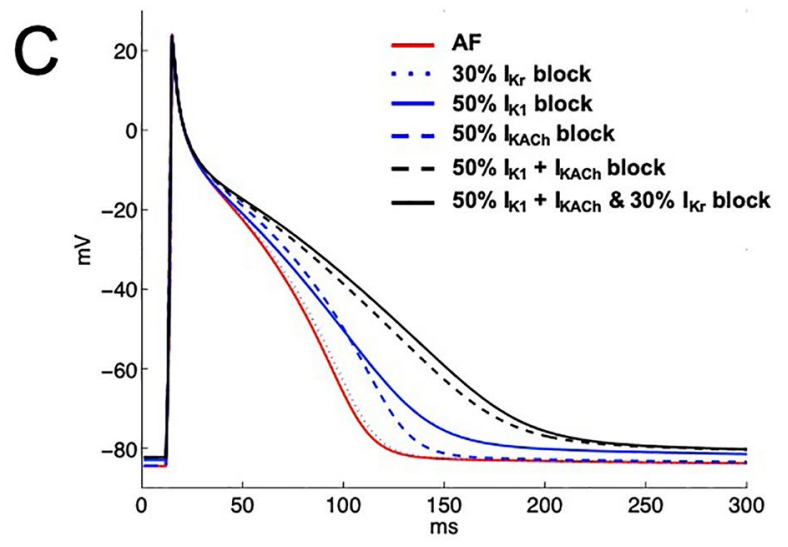

FIGURE 4 | Computational simulations of persistent AF in a 3D model of the human atria. (A) Snapshots of membrane voltage during persistent AF maintained by 2 rotors (curved arrows indicate rotation direction) in the posterior left atrium and the superior vena cava (SVC). Numbered dots indicate the locations of EGM recordings. (B) EGM traces displaying single (trace 2), double (traces 1 and 4) and fractionated (trace 3) potentials with low amplitude and high frequency of activation (DF of $11 \mathrm{~Hz}$ ). (C) Single cell left atrial action potentials, at baseline AF (red trace), when $I_{K_{r}}$ (blue dotted line), $I_{K 1}$ (blue solid line), $I_{K A C h}$ (blue dashed line), $I_{K 1}$ and $I_{K A C h}$ together (black dashed line), or the three currents together (black solid line) were blocked by $1 \mu \mathrm{M}$ of chloroquine. LIPV, and LSPV: left inferior and superior pulmonary vein. RIPV, and RSPV: right inferior and superior pulmonary vein. SVC, and IVC: superior and inferior vena cava.

Chloroquine blocks $\mathrm{I}_{\mathrm{K} 1}$ and $\mathrm{I}_{\mathrm{KACh}}$ with a similar $\mathrm{IC}_{50}$ of about $1 \mu \mathrm{M}\left(0.97 \mu \mathrm{M}\right.$ for $\mathrm{I}_{\mathrm{K} 1}$ and $1.0 \mu \mathrm{M}$ for $\left.\mathrm{I}_{\mathrm{KACh}}\right)$, this is around the plasma concentration that is achieved in patients. Additionally, chloroquine blocks $\mathrm{I}_{\mathrm{Kr}}$ with an $\mathrm{IC}_{50}$ of $2.5 \mu \mathrm{M}$. We thus tested if chloroquine block of either $\mathrm{I}_{\mathrm{K} 1}, \mathrm{I}_{\mathrm{KACh}}, \mathrm{I}_{\mathrm{Kr}}$ alone, or $\mathrm{I}_{\mathrm{K} 1}$ and $\mathrm{I}_{\mathrm{KACh}}$ together, or the three currents together terminates persistent AF. Figure 4C shows single cell left atrial action potentials when 
chloroquine was applied at $1 \mu \mathrm{M}$ in order to simulate $\sim 50 \%$ block of the $\mathrm{I}_{\mathrm{K} 1}$ and $\mathrm{I}_{\mathrm{KACh}}$ currents and $30 \%$ block of $\mathrm{I}_{\mathrm{Kr}}$. When $\mathrm{I}_{\mathrm{Kr}}$ was blocked by $30 \%$ (blue dotted line), $\mathrm{APD}_{90}$ prolonged from $98 \mathrm{~ms}$ (baseline AF, red line) to $101 \mathrm{~ms}$, without changes in the RMP $(-84.6 \mathrm{mV})$. When either $\mathrm{I}_{\mathrm{K} 1}$ or $\mathrm{I}_{\mathrm{KACh}}$ were blocked by $~ 50 \%$ (blue solid and blue dashed lines), $\mathrm{APD}_{90}$ prolonged to $133 \mathrm{~ms}$ and 118 $\mathrm{ms}$, with RMP values of $-83.0 \mathrm{mV}$ and $-84.4 \mathrm{mV}$, respectively. When both $\mathrm{I}_{\mathrm{K} 1}$ and $\mathrm{I}_{\mathrm{KACh}}$ currents were blocked by 50\% (black dashed line), $\mathrm{APD}_{90}$ prolonged to $170 \mathrm{~ms}$ and the RMP slightly depolarized to $-82.3 \mathrm{mV}$. When $\mathrm{I}_{\mathrm{K} 1}, \mathrm{I}_{\mathrm{KACh}}$ and $\mathrm{I}_{\mathrm{Kr}}$ currents were blocked by $1 \mu \mathrm{M}$ of chloroquine (black solid line), the RMP slightly depolarized to $-82.3 \mathrm{mV}$, but the $\mathrm{APD}_{90}$ prolonged to $179 \mathrm{~ms}$.

When we increased the chloroquine concentration to $2.5 \mu \mathrm{M}$ in order to simulate $\sim 70 \%$ block of the $\mathrm{I}_{\mathrm{K} 1}$ and $\mathrm{I}_{\mathrm{KACh}}$ currents and $50 \%$ block of the $\mathrm{I}_{\mathrm{Kr}}$ current, $\mathrm{APD}_{90}$ prolonged to $164 \mathrm{~ms}, 128$ $\mathrm{ms}$ and $103 \mathrm{~ms}$, with RMP of $-81.2 \mathrm{mV},-84.3 \mathrm{mV}$ and -84.6 $\mathrm{mV}$, when $\mathrm{I}_{\mathrm{K} 1}$, or $\mathrm{I}_{\mathrm{KACh}}$ or $\mathrm{I}_{\mathrm{Kr}}$ was blocked respectively. When both $\mathrm{I}_{\mathrm{K} 1}$ and $\mathrm{I}_{\mathrm{KACh}}$ were blocked by $\sim 70 \%, \mathrm{APD}_{90}$ prolonged to
$259 \mathrm{~ms}$ and the RMP depolarized to $-78.6 \mathrm{mV}$. Finally, when the three currents were blocked by $2.5 \mu \mathrm{M}$ of chloroquine, $\mathrm{APD}_{90}$ prolonged to $291 \mathrm{~ms}$, which corresponds to a $197 \%$ increase.

The two rotors maintaining $\mathrm{AF}$ at baseline continued to be present with up to $80 \% \mathrm{I}_{\mathrm{K} 1}$ or $60 \% \mathrm{I}_{\mathrm{KACh}}$ block. In such scenarios, the rotor located in the posterior wall of the left atrium near the left pulmonary vein drifted to the inferior wall and the rotor located in the superior vena cava migrated to the free wall of the right atrium. Up to $90 \%$ block of $\mathrm{I}_{\mathrm{Kr}}$ did not change the dynamics of the two rotors maintaining AF at baseline. However, when the block of $\mathrm{I}_{\mathrm{K} 1}$ reached $90 \%$ (Figure 5A) or $\mathrm{I}_{\mathrm{KACh}}$ was blocked from 70 to 90\% (Figure 5B), persistent AF converted into a stable reentrant tachycardia located at the free wall of the right atrium. In both cases, the EGMs presented single potentials generated by the wavefront emanating from the reentry and only in the posterior wall of the left atrium where the rotor wavefront pivots, some double EGMs generated by the passage of the rotor's core were observed in this area (Figures 5A, B). The DF was reduced to values between $8 \mathrm{~Hz}$

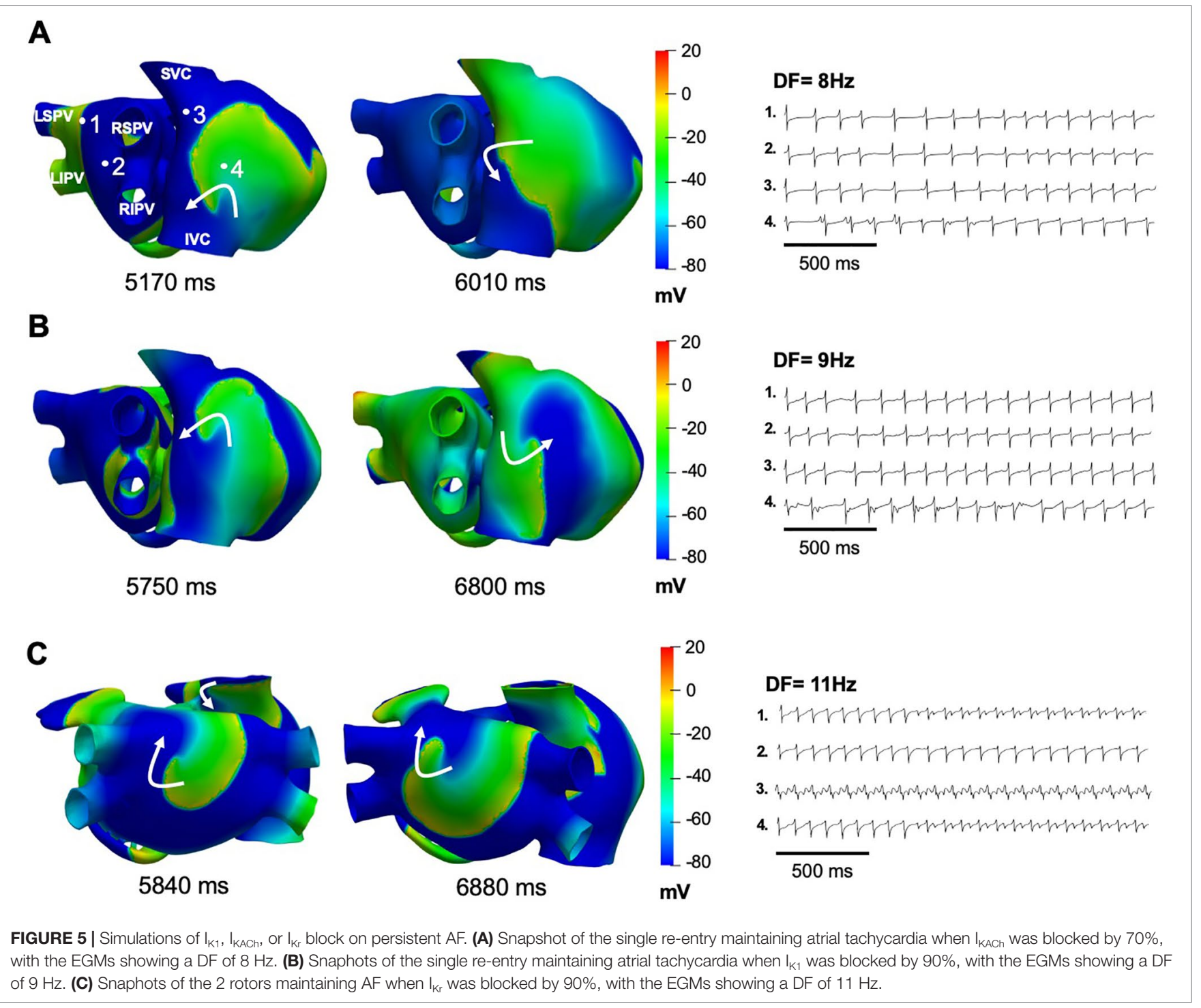


and $9 \mathrm{~Hz}$ throughout the atria. Figure $5 \mathrm{C}$ shows that AF dynamics did not change appreciably when $\mathrm{I}_{\mathrm{Kr}}$ was blocked by $90 \%$.

When the effects of chloroquine on both $\mathrm{I}_{\mathrm{K} 1}$ and $\mathrm{I}_{\mathrm{KACh}}$ together were simulated, termination of persistent $\mathrm{AF}$ was achieved with $\sim 50 \%$ block of $\mathrm{I}_{\mathrm{K} 1}$ and $\mathrm{I}_{\mathrm{KACh}}$ (Figure 6A). AF terminated $600 \mathrm{~ms}$ after the drug application, due to wavefront-wavetail interaction. Similarly, when the effects of chloroquine on the three currents together were simulated, termination of persistent $\mathrm{AF}$ was achieved with $~ 50 \%$ block of $\mathrm{I}_{\mathrm{K} 1}$ and $\mathrm{I}_{\mathrm{KACh}}$ and $30 \%$ block of $\mathrm{I}_{\mathrm{Kr}}$ (Figure 6B). AF terminated $380 \mathrm{~ms}$ after the drug application. AF terminated earlier when higher concentrations of chloroquine were simulated.

\section{DISCUSSION}

Our results showed that the aminoquinoline chloroquine blocks $\mathrm{I}_{\mathrm{K} 1}$ and $\mathrm{I}_{\mathrm{KACh}} \mathrm{V}$ by binding a pocket in the Kir2.1 and Kir3.1 channels intracellular ion permeation pathways. Moreover, chloroquine significantly reduced the burden of persistent AF in an otherwise healthy female patient. This was likely due to the ability of the drug to prolong the action potential duration, leading to a slowing down of the arrhythmia's dominant frequency, and subsequent failure of reentrant excitation due to wavefront-wavetail interaction.

Our molecular modeling suggested that chloroquine blocks $\mathrm{I}_{\mathrm{K} 1}$ and $\mathrm{I}_{\mathrm{KACh}}$ by binding to a pocket in the intracellular water filled vestibule of Kir2.1 and Kir3.1. The drug appeared to hydrogen bond with electronegative residue D260 in Kir3.1, and E224 in Kir2.1, in proximity to residue F255 in Kir3.1 and the equivalent Kir2.1 residue F254.

At baseline AF, our simulations showed EGMs with double and fractionated potentials with low amplitude and high frequency when the tip of the rotors pivoted on the recording points (pivot point). Experimental and clinical studies of AF have documented intracardiac polymorphic EGMs in high frequency areas with fibrillatory conduction (Ryu et al., 2006; Kalifa et al., 2006; Narayan and Krummen, 2012; Narayan et al., 2012a; Narayan et al., 2012b; Narayan et al., 2012c; Narayan et al., 2012d) and fractionated EGMs when the rotor core passes at the recording point (Zlochiver et al., 2008). When $I_{K 1}$ or $\mathrm{I}_{\mathrm{KACh}}$ were individually blocked with increasing concentrations of chloroquine AF organized into reentrant atrial tachycardia due to APD prolongation. EGMs with single potentials in the atria were observed, characteristic of EGMs recorded during atrial tachycardias (Ryu et al., 2006). Double potentials were generated by the passage of the reentry core at the recording point in the free wall of the right atrium. It has been reported that atrial potentials consisting of two or more deflections can be recorded during atrial tachycardias in sites of earliest activation such as the crista terminalis (De Groot and Schalij, 2006). When only $I_{\mathrm{Kr}}$ was blocked, AF dynamics did not change

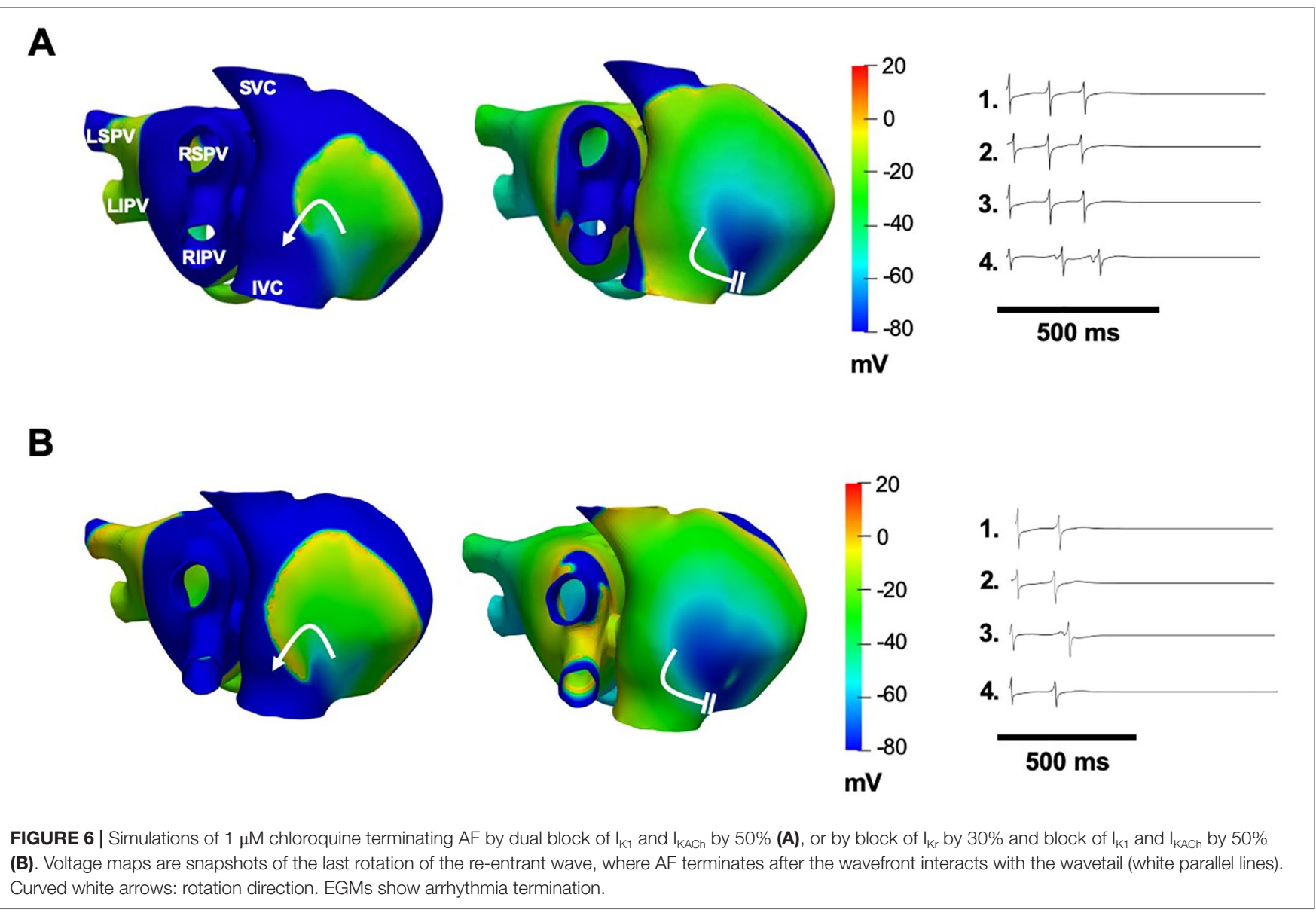


(Figure 5C) because $\mathrm{I}_{\mathrm{Kr}}$ block had a minimal effect on the APD (Figure 4C). While it has been reported that chloroquine is an $\mathrm{I}_{\mathrm{Kr}}$ blocker (Sanchez-Chapula et al., 2002; Traebert et al., 2004), and can prolong the QT interval (White, 2007; Stas et al., 2008), in our simulations $\mathrm{I}_{\mathrm{Kr}}$ block did not contribute substantially to the atrial antiarrhythmic properties. This could be in part due to the lower expression of hERG channels in the atria compared to the ventricles (Pond et al., 2000). When both $\mathrm{I}_{\mathrm{K} 1}$ and $\mathrm{I}_{\mathrm{KACh}}$ (Figure 6A) or $\mathrm{I}_{\mathrm{K} 1}, \mathrm{I}_{\mathrm{KACh}}$ and $\mathrm{I}_{\mathrm{Kr}}$ (Figure 6B) were blocked by 1 $\mu \mathrm{M}$ chloroquine, AF terminated.

The oral chloroquine regimen which we administered to a patient with persistent $\mathrm{AF}$ consisted of $600 \mathrm{mg}$ chloroquine base once daily, for 2 days, followed by $300 \mathrm{mg}$ once daily for 12 days. Therapeutic doses of chloroquine typically result in plasma concentrations around $1 \mu \mathrm{M}$ (Karunajeewa et al., 2010), within the range of $\mathrm{IC}_{50}$ of $\mathrm{I}_{\mathrm{KACh}}$ and $\mathrm{I}_{\mathrm{K} 1}$ block by the drug. The cardiac safety of chloroquine when used correctly is well documented. For instance, from cardiac electrophysiological safety standpoint, chloroquine is safe. This was shown in a large cohort of patients with systemic lupus erythematosus who have been treated with chloroquine for an average of 8 years. Chloroquine was found to be not only electrophysiologically safe, but to also have antiarrhythmic activity in those patients with autoimmune disease (Wozniacka et al., 2006; Teixeira et al., 2014). Chloroquine poisoning occurs with ingestion of more than $5 \mathrm{~g}$ of chloroquine per dose (Riou et al., 1988).

Presently, the treatment of persistent AF remains inadequate (Rietbrock et al., 2008; Shukla and Curtis, 2014). Clinical studies demonstrated that antiarrhythmics, or ablation strategies do not result in complete freedom from AF, thus antiarrhythmic drug therapy remains an important line of defense. With currently used antiarrhythmics, the rate of conversion to sinus rhythms is not optimal (Zimetbaum, 2012). Additionally, toxicities including life threatening arrhythmogenesis are a significant risk in antiarrhythmic rhythm control pharmacotherapy. Nevertheless, pharmacological maintenance of sinus rhythm offers secondary end point benefits such as improvement in left ventricular function, walking distance, in addition to atrial size reduction (Chung et al., 2005; Hagens et al., 2005; Rienstra et al., 2005). Hence, there is a need to improve the antiarrhythmic armamentarium, and to generate novel antiarrhythmics that are safe and that can reduce the burden of persistent AF or restore sinus rhythm. Based on this study and those of others, chloroquine appears to have antiarrhythmic properties in patients with AF (Burrell and Martinez, 1958; Harris et al., 1988). On the other hand, chloroquine's known side effects include QT prolongation (White, 2007; Stas et al., 2008), and retinal and gastrointestinal adverse reactions (Al-Bari, 2015). Therefore, using rational design to discover novel inward rectifier blockers based on small aminoquinolines such as chloroquine, but with an improved safety profile, could offer new avenues in the search of new pharmacotherapies for AF.

The combination of $3 \mathrm{D}$ virtual models of atrial fibrillation with modeling of ion channel block by small molecules opens the door for the simulation of antiarrhythmic drug effects, leading the way for the development of a more effective and safer generation of anti AF agents.

\section{LIMITATIONS}

Atrial remodeling in persistent $\mathrm{AF}$ is complex, with many changes occurring from the transcriptional to post-translational levels (Anisimov and Boheler, 2003; Volkova et al., 2005). In addition, autonomic, anatomical, sarcolemmal, and subsarcolemmal electrophysiological remodeling has been described in persistent AF, resulting in slow and discontinuous electrical propagation, and aberrant excitation-contraction coupling, as well as increased perpetuation of AF (Kumar et al., 2012). For instance, increased fibrosis (Koura et al., 2002), reduced $\mathrm{I}_{\mathrm{CaL}}$, increased background inward rectifiers currents ( $\mathrm{I}_{\mathrm{K} 1}$ and constitutively active $\mathrm{I}_{\mathrm{KACh}}$ ) in addition to mitochondrial (Moslehi et al., 2012), and calcium handling abnormalities (Vest et al., 2005) are present in persistent AF. Such changes can play a significant role in creating the complex structural and functional substrates which promote the initiation and maintenance of high speed rotors responsible for atrial fibrillation. Therefore, it not unlikely that chloroquine's effect is not exclusively due to the block of $\mathrm{I}_{\mathrm{KACh}}$ and $\mathrm{I}_{\mathrm{K} 1}$. At the therapeutic chloroquine plasma concentration, which is around $1 \mu \mathrm{M}$, the drug blocks about $14 \%$ of the $\mathrm{I}_{\mathrm{Na}}$ current, $7 \%$ of the $\mathrm{I}_{\mathrm{CaL}}$, and $9 \%$ of $\mathrm{I}_{\mathrm{Ks}}$ (SanchezChapula et al., 2001). It thus becomes conceivable that the multitarget effect of chloroquine contributed to its antiarrhythmic properties in persistent AF.

Although the electrophysiological remodeling conditions that we used in our simulations can reproduce the action potential phenotype observed in patients with persistent $\mathrm{AF}$, as mentioned above, they do not take into account the significant structural remodeling that is found in the chronically fibrillating atria, which increases the complexity of the arrhythmia. Additionally, our numerical results were obtained using a specific virtual atria model that lacks fibrosis, albeit it includes a great number of anatomical and morphological details including electrophysiology, anatomy, fiber direction, anisotropy, and heterogeneity. Although functional reentries and rotors have been widely reported as maintenance mechanisms of AF, future works must include structural remodeling in order to address how chloroquine may be antiarrhythmic when ionic and structural remodeling are the driving mechanisms of persistent AF.

The simulated results may be atrial cell model-dependent. For instance, other human atrial models show a more triangular action potential and have a flatter restitution curve, however, all models introduce ionic remodeling in a similar way, resulting in effects on the action potential that are similar to what our simulations suggest. These models generally include decreases in $\mathrm{I}_{\mathrm{to}}, \mathrm{I}_{\mathrm{CaL}}$ and $\mathrm{I}_{\mathrm{Kur}}$, and increased $\mathrm{I}_{\mathrm{K} 1}$. More recently, AF models that also account for the remodeling of intracellular $\mathrm{Ca}^{2+}$ handling have been developed (Grandi et al., 2011; Skibsbye et al., 2016; Colman et al., 2017; Bai et al., 2018). However, the simpler $\mathrm{I}_{\mathrm{to}} / \mathrm{I}_{\mathrm{CaL}} /$ $\mathrm{I}_{\mathrm{Kur}} / \mathrm{I}_{\mathrm{K} 1}$ approach of persistent AF modeling remains commonly used, and we do not think that the use of a more complex model would substantially change the main results of our work. For modeling the effects of $\mathrm{I}_{\mathrm{Kr}}$ block by chloroquine, we did not perform a concentration-response curve of the current block by the drug. We relied instead on the literature reported $\mathrm{IC}_{50}$ of 2.5 
$\mu \mathrm{M}$ (Traebert et al., 2004), and thus, it is possible that variations around this value could affect the simulation results.

Two studies have reported that a benzopyrene derivative (Podd et al., 2016) and a benzamide related compound (Walfridsson et al., 2015) selectively inhibited $\mathrm{I}_{\mathrm{KACh}}$. However, the drugs failed in patients with paroxysmal AF and atrial flutter (Walfridsson et al., 2015; Podd et al., 2016). This could be because $\mathrm{I}_{\mathrm{KACh}}$ is not constitutively active in paroxysmal AF (Voigt et al., 2007) and mechanistically, atrial flutter is very different from AF (Olshansky, 2004). Consequently, inhibiting $\mathrm{I}_{\mathrm{KACh}}$ as part of an antiarrhythmic pharmaco-strategy should be reserved for the patient population in which the current is known to play a role. On the other hand, it is possible that chloroquine would reduce the burden of paroxysmal AF. It was shown that in patients with paroxysmal AF, a left/ right atrial gradient in $\mathrm{I}_{\mathrm{K} 1}$ exists (Voigt et al., 2010). This gradient could contribute to the ionic mechanism of paroxysmal AF, and therefore block of $\mathrm{I}_{\mathrm{K} 1}$ by chloroquine might be antiarrhythmic. Chloroquine might have limited antiarrhythmic effects in atrial flutter since its mechanisms are distinct from those of AF (Olshansky, 2004).

This is a proof of concept study which showed that chloroquine reduced persistent $A F$ burden in a single patient. $I_{K 1}$ and $I_{K A C h}$ block is proposed as a plausible mechanism for this reduction as suggested by the numerical simulations. Further studies are needed in order to demonstrate a relation between $\mathrm{I}_{\mathrm{KACh}}$ and $\mathrm{I}_{\mathrm{K} 1}$ block and reduction of persistent AF burden.

\section{REFERENCES}

Al-Bari, M. A. (2015). Chloroquine analogues in drug discovery: new directions of uses, mechanisms of actions and toxic manifestations from malaria to multifarious diseases. J. Antimicrob. Chemother. 70, 1608-1621. doi: 10.1093/jac/dkv018

Anisimov, S. V., and Boheler, K. R. (2003). Aging-associated changes in cardiac gene expression: large scale transcriptome analysis. Advances in gerontology = Uspekhi gerontologii / Rossiiskaia akademiia nauk. Gerontol. Obshchestvo 11, 67-75.

Atienza, F., and Jalife, J. (2007). Reentry and atrial fibrillation. Heart Rhythm.: Off. J. Heart Rhythm. Soc. 4, S13-S16. doi: 10.1016/j.hrthm.2006.12.004

Bai, J., Gladding, P. A., Stiles, M. K., Fedorov, V. V., and Zhao, J. (2018). Ionic and cellular mechanisms underlying TBX5/PITX2 insufficiency-induced atrial fibrillation: Insights from mathematical models of human atrial cells. Sci. Rep. 8, 15642. doi: 10.1038/s41598-018-33958-y

Burrell, Z. L. Jr., and Martinez, A. C. (1958). Chloroquine and hydroxychloroquine in the treatment of cardiac arrhythmias. New Engl. J. Med. 258, 798-800. doi: 10.1056/NEJM195804172581608

Chung, M. K., Shemanski, L., Sherman, D. G., Greene, H. L., Hogan, D. B., Kellen, J. C., et al. (2005). Functional status in rate- versus rhythm-control strategies for atrial fibrillation: results of the Atrial Fibrillation Follow-Up Investigation of Rhythm Management (AFFIRM) Functional Status Substudy. J. Am. Coll. Cardiol. 46, 1891-1899. doi: 10.1016/j.jacc.2005.07.040

Colman, M. A., Pinali, C., Trafford, A. W., Zhang, H., and Kitmitto, A. (2017). A computational model of spatio-temporal cardiac intracellular calcium handling with realistic structure and spatial flux distribution from sarcoplasmic reticulum and t-tubule reconstructions. PloS Comput. Biol. 13, e1005714. doi: 10.1371/journal.pcbi.1005714

Courtemanche, M., Ramirez, R. J., and Nattel, S. (1998). Ionic mechanisms underlying human atrial action potential properties: insights from a mathematical model. Am. J. Physiol. 275, H301-H321. doi: 10.1152/ajpheart.1998.275.1.H301

DeGroot, N.M., and Schalij, M.J.(2006). Fragmented,long-duration,low-amplitude electrograms characterize the origin of focal atrial tachycardia. J. Cardiovasc. Electrophysiol. 17, 1086-1092. doi: 10.1111/j.1540-8167.2006.00568.x

\section{DATA AVAILABILITY STATEMENT}

All datasets generated for this study are included in the article/ supplementary material.

\section{ETHICS STATEMENT}

The studies involving human participants were reviewed and approved by USF IRB. The patients/participants provided their written informed consent to participate in this study.

\section{AUTHOR CONTRIBUTIONS}

Designed Research: CT, LP, BC, DPS, TT, NT, MR, Y-SL, BH, DS, JS, and SN. Analyzed data: CT, LP, BC, DPS, Y-SL, BH, DS, JS, and SN. Wrote manuscript: CT, LP, BC, DPS, BH, JS, and SN.

\section{FUNDING}

This work was supported in part by National Institutes of Health grants R21HL138064, R01HL129136, by the Dirección General de Política Científica de la Generalitat Valenciana (PROMETEO 2016/088), and by the ACM SIGHPC/Intel Computational \& Data Science fellowship.

Dobrev, D., and Nattel, S. (2011). New insights into the molecular basis of atrial fibrillation: mechanistic and therapeutic implications. Cardiovasc. Res. 89, 689-691. doi: 10.1093/cvr/cvr021

Duarte M, R. A., Tobón, C., Cardona, K., and Saiz, J. (2013). Chloroquine effect on human atrial action potential under normal conditions and during paroxysmal and chronic atrial fibrillation. Columbia:A simulation study, PAHCE, 71-75. doi: 10.1109/PAHCE.2013.6568230

Filgueiras-Rama, D., Martins, R. P., Mironov, S., Yamazaki, M., Calvo, C. J., Ennis, S. R., et al. (2012). Chloroquine terminates stretch-induced atrial fibrillation more effectively than flecainide in the sheep heart. Circ. Arrhythmia Electrophysiol. 5, 561-570. doi: 10.1161/CIRCEP.111.966820

Grandi, E., Pandit, S. V., Voigt, N., Workman, A. J., Dobrev, D., Jalife, J., et al. (2011). Human atrial action potential and $\mathrm{Ca} 2+$ model: sinus rhythm and chronic atrial fibrillation. Circ. Res. 109, 1055-1066. doi: 10.1161/CIRCRESAHA. 111.253955

Greenwood, J. R., Calkins, D., Sullivan, A. P., and Shelley, J. C. (2010). Towards the comprehensive, rapid, and accurate prediction of the favorable tautomeric states of drug-like molecules in aqueous solution. J. Computer-aided Mol. Design 24, 591-604. doi: 10.1007/s10822-010-9349-1

Hagens, V. E., Van Veldhuisen, D. J., Kamp, O., Rienstra, M., Bosker, H. A., Veeger, N. J., et al. (2005).Effect of rate and rhythm control on left ventricular function and cardiac dimensions in patients with persistent atrial fibrillation: results from the RAte Control versus Electrical Cardioversion for Persistent Atrial Fibrillation (RACE) study. Heart Rhythm.: Off. J. Heart Rhythm. Soc. 2, 19-24. doi: 10.1016/j.hrthm.2004.09.028

Harris, L., Downar, E., Shaikh, N. A., and Chen, T. (1988). Antiarrhythmic potential of chloroquine: new use for an old drug. Can. J. Cardiol. 4, 295-300.

Heidenreich, E. A., Ferrero, J. M., Doblare, M., and Rodriguez, J. F. (2010).Adaptive macro finite elements for the numerical solution of monodomain equations in cardiac electrophysiology. Ann. Biomed. Eng. 38, 2331-2345. doi: 10.1007/ s10439-010-9997-2

Humphrey, W., Dalke, A., and Schulten, K. (1996). VMD: visual molecular dynamics. J. Mol. Graphics 14, 33-8, 27-8. doi: 10.1016/0263-7855(96)00018-5 
Iijima, H., Dunbar, J. B. Jr., and Marshall, G. R. (1987). Calibration of effective van der Waals atomic contact radii for proteins and peptides. Proteins 2, 330-339. doi: 10.1002/prot.340020408

Kalifa, J., Tanaka, K., Zaitsev, A. V., Warren, M., Vaidyanathan, R., Auerbach, D., et al. (2006). Mechanisms of wave fractionation at boundaries of highfrequency excitation in the posterior left atrium of the isolated sheep heart during atrial fibrillation. Circulation 113, 626-633. doi: 10.1161/ CIRCULATIONAHA.105.575340

Karunajeewa, H. A., Salman, S., Mueller, I., Baiwog, F., Gomorrai, S., Law, I., et al. (2010). Pharmacokinetics of chloroquine and monodesethylchloroquine in pregnancy. Antimicrob. Agents Chemother. 54, 1186-1192. doi: 10.1128/ AAC.01269-09

Kneller, J., Zou, R., Vigmond, E. J., Wang, Z., Leon, L. J., and Nattel, S. (2002). Cholinergic atrial fibrillation in a computer model of a two-dimensional sheet of canine atrial cells with realistic ionic properties. Circ. Res. 90, E73-E87. doi: 10.1161/01.RES.0000019783.88094.BA

Koura, T., Hara, M., Takeuchi, S., Ota, K., Okada, Y., Miyoshi, S., et al. (2002). Anisotropic conduction properties in canine atria analyzed by high-resolution optical mapping: preferential direction of conduction block changes from longitudinal to transverse with increasing age. Circulation 105, 2092-2098. doi: 10.1161/01.CIR.0000015506.36371.0D

Kumar, S., Teh, A. W., Medi, C., Kistler, P. M., Morton, J. B., and Kalman, J. M. (2012). Atrial remodeling in varying clinical substrates within beating human hearts: relevance to atrial fibrillation. Prog. In Biophys. Mol. Biol. 110, 278-294. doi: 10.1016/j.pbiomolbio.2012.07.011

Liao, J. N., Chao, T. F., Liu, C. J., Wang, K. L., Chen, S. J., Tuan, T. C., et al. (2015). Risk and prediction of dementia in patients with atrial fibrillation-a nationwide population-based cohort study. Int. J. Cardiol. 199, 25-30. doi: 10.1016/j.ijcard.2015.06.170

Mahler, J., and Persson, I. (2012). A study of the hydration of the alkali metal ions in aqueous solution. Inorg. Chem. 51, 425-438. doi: 10.1021/ic2018693

Morris, G. M., Huey, R., Lindstrom, W., Sanner, M. F., Belew, R. K., Goodsell, D. S., et al. (2009). AutoDock4 and AutoDockTools4: Automated docking with selective receptor flexibility. J. Comput. Chem. 30, 2785-2791. doi: 10.1002/ jcc. 21256

Moslehi, J., DePinho, R. A., and Sahin, E. (2012). Telomeres and mitochondria in the aging heart. Circ. Res. 110, 1226-1237. doi: 10.1161/CIRCRESAHA.111.246868

Narayan, S. M., and Krummen, D. E. (2012). Targeting Stable Rotors to Treat Atrial Fibrillation. Arrhythm Electrophysiol. Rev. 1, 34-38. doi: 10.15420/ aer.2012.1.34

Narayan, S. M., Krummen, D. E., Enyeart, M. W., and Rappel, W. J. (2012a). Computational mapping identifies localized mechanisms for ablation of atrial fibrillation. PloS One 7, e46034. doi: 10.1371/journal.pone.0046034

Narayan, S. M., Krummen, D. E., and Rappel, W. J. (2012b). Clinical mapping approach to diagnose electrical rotors and focal impulse sources for human atrial fibrillation. J. Cardiovasc. Electrophysiol. 23, 447-454. doi: 10.1111/j.1540-8167.2012.02332.x

Narayan, S. M., Krummen, D. E., Shivkumar, K., Clopton, P., Rappel, W. J., and Miller, J. M. (2012c). Treatment of atrial fibrillation by the ablation of localized sources: CONFIRM (Conventional Ablation for Atrial Fibrillation With or Without Focal Impulse and Rotor Modulation) trial. J. Am. Coll. Cardiol. 60, 628-636. doi: 10.1016/j.jacc.2012.05.022

Narayan, S. M., Patel, J., Mulpuru, S., and Krummen, D. E. (2012d). Focal impulse and rotor modulation ablation of sustaining rotors abruptly terminates persistent atrial fibrillation to sinus rhythm with elimination on follow-up: a video case study. Heart Rhythm.: Off. J. Heart Rhythm. Soc. 9, 1436-1439. doi: 10.1016/j.hrthm.2012.03.055

Noujaim, S. F., Pandit, S. V., Berenfeld, O., Vikstrom, K., Cerrone, M., Mironov, S., et al. (2007). Up-regulation of the inward rectifier K+ current (I K1) in the mouse heart accelerates and stabilizes rotors. J. Physiol. 578, 315-326. doi: 10.1113/jphysiol.2006.121475

Noujaim, S. F., Stuckey, J. A., Ponce-Balbuena, D., Ferrer-Villada, T., LopezIzquierdo, A., Pandit, S., et al. (2010). Specific residues of the cytoplasmic domains of cardiac inward rectifier potassium channels are effective antifibrillatory targets. FASEB J.: Off. Publ. Fed. Am. Soc. Exp. Biol. 24, 43024312. doi: 10.1096/fi.10-163246

Noujaim, S. F., Stuckey, J. A., Ponce-Balbuena, D., Ferrer-Villada, T., LopezIzquierdo, A., Pandit, S. V., et al. (2011). Structural bases for the different anti-fibrillatory effects of chloroquine and quinidine. Cardiovasc. Res. 89, 862 869. doi: $10.1093 / \mathrm{cvr} / \mathrm{cvr} 008$

Olshansky, B. (2004). Combining ablation of atrial fibrillation with ablation of atrial flutter: are we there yet? J. Am. Coll. Cardiol. 43, 2063-2065. doi: 10.1016/j.jacc.2004.03.020

Pegan, S., Arrabit, C., Zhou, W., Kwiatkowski, W., Collins, A., Slesinger, P. A., et al. (2005). Cytoplasmic domain structures of Kir2.1 and Kir3.1 show sites for modulating gating and rectification. Nat. Neurosci. 8, 279-287. doi: 10.1038/ nn1411

Podd, S. J., Freemantle, N., Furniss, S. S., and Sulke, N. (2016). First clinical trial of specific IKACh blocker shows no reduction in atrial fibrillation burden in patients with paroxysmal atrial fibrillation: pacemaker assessment of BMS 914392 in patients with paroxysmal atrial fibrillation. Eur.: Eur. Pacing Arrhythmias Cardiac Electrophysiol.: J. Working Groups Cardiac Pacing Arrhythmias Cardiac Cell. Electrophysiol. Eur. Soc. Cardiol. 18, 340-346. doi: 10.1093/europace/euv263

Pond, A. L., Scheve, B. K., Benedict, A. T., Petrecca, K., Van Wagoner, D. R., Shrier, A., et al. (2000). Expression of distinct ERG proteins in rat, mouse, and human heart. Relat. Funct. I(Kr) Channels J. Biol. Chem. 275, 5997-6006. doi: $10.1074 /$ jbc.275.8.5997

Rienstra, M., Van Veldhuisen, D. J., Hagens, V. E., Ranchor, A. V., Veeger, N. J., Crijns, H. J., et al. (2005). Gender-related differences in rhythm control treatment in persistent atrial fibrillation: data of the Rate Control Versus Electrical Cardioversion (RACE) study. J. Am. Coll. Cardiol. 46, 1298-1306. doi: 10.1016/j.jacc.2005.05.078

Rietbrock, S., Heeley, E., Plumb, J., and van Staa, T. (2008). Chronic atrial fibrillation: Incidence, prevalence, and prediction of stroke using the Congestive heart failure, Hypertension, Age $>75$, Diabetes mellitus, and prior Stroke or transient ischemic attack (CHADS2) risk stratification scheme. Am. Heart J. 156, 57-64. doi: 10.1016/j.ahj.2008.03.010

Riou, B., Barriot, P., Rimailho, A., and Baud, F. J. (1988). Treatment of severe chloroquine poisoning. New Engl. J. Med. 318, 1-6. doi: 10.1056/ NEJM198801073180101

Rodriguez-Menchaca, A. A., Navarro-Polanco, R. A., Ferrer-Villada, T., Rupp, J., Sachse, F. B., Tristani-Firouzi, M., et al. (2008). The molecular basis of chloroquine block of the inward rectifier Kir2.1 channel. Proc. Natl. Acad. Sci. U. States America 105, 1364-1368. doi: 10.1073/pnas.0708153105

Ryu, K., Sahadevan, J., Khrestian, C. M., Stambler, B. S., and Waldo, A. L. (2006). Use of fast fourier transform analysis of atrial electrograms for rapid characterization of atrial activation-implications for delineating possible mechanisms of atrial tachyarrhythmias. J. Cardiovasc. Electrophysiol. 17, 198206. doi: 10.1111/j.1540-8167.2005.00320.x

Sanchez-Chapula, J. A., Salinas-Stefanon, E., Torres-Jacome, J., BenavidesHaro, D. E., and Navarro-Polanco, R. A. (2001). Blockade of currents by the antimalarial drug chloroquine in feline ventricular myocytes. J. Pharmacol. Exp. Ther. 297, 437-445.

Sanchez-Chapula, J. A., Navarro-Polanco, R. A., Culberson, C., Chen, J., and Sanguinetti, M. C. (2002). Molecular determinants of voltage-dependent human ether-a-go-go related gene (HERG) K+ channel block. J. Biol. Chem. 277, 23587-23595. doi: 10.1074/jbc.M200448200

Sastry, G. M., Adzhigirey, M., Day, T., Annabhimoju, R., and Sherman, W. (2013). Protein and ligand preparation: parameters, protocols, and influence on virtual screening enrichments. J. Computer-aided Mol. Design 27, 221-234. doi: 10.1007/s10822-013-9644-8

Schotten, U., Greiser, M., Benke, D., Buerkel, K., Ehrenteidt, B., Stellbrink, C., et al. (2002). Atrial fibrillation-induced atrial contractile dysfunction: a tachycardiomyopathy of a different sort. Cardiovasc. Res. 53, 192-201. doi: 10.1016/S0008-6363(01)00453-9

Shelley, J. C., Cholleti, A., Frye, L. L., Greenwood, J. R., Timlin, M. R., and Uchimaya, M. (2007). Epik: a software program for $\mathrm{pK}$ ( a ) prediction and protonation state generation for drug-like molecules. J. Computer-aided Mol. Design 21, 681-691. doi: 10.1007/s10822-007-9133-Z

Shivakumar, D., Williams, J., Wu, Y., Damm, W., Shelley, J., and Sherman, W. (2010). Prediction of Absolute Solvation Free Energies using Molecular Dynamics Free Energy Perturbation and the OPLS Force Field. J. Chem. Theory Comput. 6, 1509-1519. doi: 10.1021/ct900587b

Shukla, A., and Curtis, A. B. (2014). Avoiding permanent atrial fibrillation: treatment approaches to prevent disease progression. Vasc. Health Risk Manage. 10, 1-12. doi: 10.2147/VHRM.S49334 
Singh-Manoux, A., Fayosse, A., Sabia, S., Canonico, M., Bobak, M., Elbaz, A., et al. (2017). Atrial fibrillation as a risk factor for cognitive decline and dementia. Eur. Heart J. 38, 2612-2618. doi: 10.1093/eurheartj/ehx208

Skibsbye, L., Jespersen, T., Christ, T., Maleckar, M. M., van den Brink, J., Tavi, P., et al. (2016). Refractoriness in human atria: Time and voltage dependence of sodium channel availability. J. Mol. Cell. Cardiol. 101, 26-34. doi: 10.1016/j. yjmcc.2016.10.009

Stas, P., Faes, D., and Noyens, P. (2008). Conduction disorder and QT prolongation secondary to long-term treatment with chloroquine. Int. J. Cardiol. 127, e80e82. doi: 10.1016/j.ijcard.2007.04.055

Takemoto, Y., Slough, D. P., Meinke, G., Katnik, C., Graziano, Z. A., Chidipi, B., et al. (2018). Structural basis for the antiarrhythmic blockade of a potassium channel with a small molecule. FASEB J.: Off. Publ. Fed. Am. Soc. Exp. Biol. 32, 1778-1793. doi: 10.1096/fj.201700349R

Teixeira, R. A., Borba, E. F., Pedrosa, A., Nishioka, S., Viana, V. S., Ramires, J. A., et al. (2014). Evidence for cardiac safety and antiarrhythmic potential of chloroquine in systemic lupus erythematosus. Eur.: Eur. Pacing Arrhythmias Cardiac Electrophysiol.: J. Working Groups Cardiac Pacing Arrhythmias Cardiac Cell. Electrophysiol. Eur. Soc. Cardiol. 16, 887-892. doi: 10.1093/ europace/eut 290

Tobon, C., Ruiz-Villa, C. A., Heidenreich, E., Romero, L., Hornero, F., and Saiz, J. (2013). A three-dimensional human atrial model with fiber orientation. Electrograms Arrhythmic Activation Patterns Relat. PloS One 8, e50883. doi: 10.1371/journal.pone.0050883

Traebert, M., Dumotier, B., Meister, L., Hoffmann, P., Dominguez-Estevez, M., and Suter, W. (2004). Inhibition of hERG K+ currents by antimalarial drugs in stably transfected HEK293 cells. Eur. J. Pharmacol. 484, 41-48. doi: 10.1016/j. ejphar.2003.11.003

Van Wagoner, D. R. (2003). Electrophysiological remodeling in human atrial fibrillation. Pacing Clin. Electrophysiol. : PACE 26, 1572-1575. doi: 10.1046/ j.1460-9592.2003.t01-1-00234.x

Vest, J. A., Wehrens, X. H., Reiken, S. R., Lehnart, S. E., Dobrev, D., Chandra, P., et al. (2005). Defective cardiac ryanodine receptor regulation during atrial fibrillation. Circulation 111, 2025-2032. doi: 10.1161/01. CIR.0000162461.67140.4C

Voigt, N., Friedrich, A., Bock, M., Wettwer, E., Christ, T., Knaut, M., et al. (2007). Differential phosphorylation-dependent regulation of constitutively active and muscarinic receptor-activated IK,ACh channels in patients with chronic atrial fibrillation. Cardiovasc. Res. 74, 426-437. doi: 10.1016/j. cardiores.2007.02.009

Voigt, N., Trausch, A., Knaut, M., Matschke, K., Varro, A., Van Wagoner, D. R., et al. (2010). Left-to-right atrial inward rectifier potassium current gradients in patients with paroxysmal versus chronic atrial fibrillation. Circ. Arrhythmia Electrophysiol. 3, 472-480. doi: 10.1161/CIRCEP.110.954636
Volkova, M., Garg, R., Dick, S., and Boheler, K. R. (2005). Aging-associated changes in cardiac gene expression. Cardiovasc. Res. 66, 194-204. doi: 10.1016/j.cardiores.2004.11.016

Walfridsson, H., Anfinsen, O. G., Berggren, A., Frison, L., Jensen, S., Linhardt, G., et al. (2015). Is the acetylcholine-regulated inwardly rectifying potassium current a viable antiarrhythmic target? Translational discrepancies of AZD2927 and A7071 in dogs and humans. Eur. : Eur. Pacing Arrhythmias Cardiac Electrophysiol. : J. Working Groups Cardiac Pacing Arrhythmias Cardiac Cell. Electrophysiol. Eur. Soc. Cardiol. 17, 473-482. doi: 10.1093/europace/euu192

White, N. J. (2007). Cardiotoxicity of antimalarial drugs. Lancet Infect. Dis. 7, 549-558. doi: 10.1016/S1473-3099(07)70187-1

Wishart, D. S., Knox, C., Guo, A. C., Cheng, D., Shrivastava, S., Tzur, D., et al. (2008). DrugBank: a knowledgebase for drugs, drug actions and drug targets. Nucleic Acids Res. 36, D901-D906. doi: 10.1093/nar/gkm958

Wolf, P. A., Abbott, R. D., and Kannel, W. B. (1991). Atrial fibrillation as an independent risk factor for stroke: the Framingham Study. Stroke; J. Cereb. Circ. 22, 983-988. doi: 10.1161/01.STR.22.8.983

Workman, A. J., Kane, K. A., and Rankin, A. C. (2001). The contribution of ionic currents to changes in refractoriness of human atrial myocytes associated with chronic atrial fibrillation. Cardiovasc. Res. 52, 226-235. doi: 10.1016/ S0008-6363(01)00380-7

Wozniacka, A., Cygankiewicz, I., Chudzik, M., Sysa-Jedrzejowska, A., and Wranicz, J. K. (2006). The cardiac safety of chloroquine phosphate treatment in patients with systemic lupus erythematosus: the influence on arrhythmia, heart rate variability and repolarization parameters. Lupus 15, 521-525. doi: 10.1191/0961203306lu2345oa

Zimetbaum, P. (2012). Antiarrhythmic drug therapy for atrial fibrillation. Circulation 125, 381-389. doi: 10.1161/CIRCULATIONAHA.111.019927

Zlochiver, S., Yamazaki, M., Kalifa, J., and Berenfeld, O. (2008). Rotor meandering contributes to irregularity in electrograms during atrial fibrillation. Heart Rhythm. : Off. J. Heart Rhythm. Soc. 5, 846-854. doi: 10.1016/j. hrthm.2008.03.010

Conflict of Interest: The authors declare that the research was conducted in the absence of any commercial or financial relationships that could be construed as a potential conflict of interest.

Copyright (C) 2019 Tobón, Palacio, Chidipi, Slough, Tran, Tran, Reiser, Lin, Herweg, Sayad, Saiz and Noujaim. This is an open-access article distributed under the terms of the Creative Commons Attribution License (CC BY). The use, distribution or reproduction in other forums is permitted, provided the original author(s) and the copyright owner(s) are credited and that the original publication in this journal is cited, in accordance with accepted academic practice. No use, distribution or reproduction is permitted which does not comply with these terms. 